\title{
Infant mortality and congenital anomalies from 1950 to 1994: an international perspective
}

\author{
Aldo Rosano, Lorenzo D Botto, Beverley Botting, Pierpaolo Mastroiacovo
}

\begin{abstract}
Study objective-To provide an international perspective on the impact of congenital anomalies on infant mortality from 1950 to 1994.

Design-Population-based study based on data obtained from vital statistics reported to the World Health Organisation. Settings-36 countries from Europe, the Middle East, the Americas, Asia, and the South Pacific.

Results-On average, infant mortality declined 68.8 per cent from 1950 to 1994 . In the countries studied, infant mortality attributable to congenital anomalies decreased by 33.4 per cent, although it recently increased in some countries in Central and Latin America and in Eastern Europe. Anomalies of the heart and of the central nervous system accounted for 48.9 per cent of infant deaths attributable to congenital anomalies. During 1990-1994, infant mortality attributable to congenital anomalies was inversely correlated to the per capita gross domestic product in the countries studied. At the same time, the proportion of infant deaths attributable to congenital malformations was directly correlated with the per capita gross domestic product.
\end{abstract}

Conclusions-Congenital malformations account for an increasing proportion of infant deaths in both developed and developing countries. Infant mortality attributable to congenital anomalies is higher in poorer countries although as a proportion of infant deaths it is greater in wealthier countries. Conditions such as spina bifida, whose occurrence can be reduced through preventive strategies, still cause many infant deaths. The apparent increase of infant mortality because of congenital anomalies in some countries should be investigated to confirm the finding, find the causes, and provide prevention opportunities.

(F Epidemiol Community Health 2000;54:660-666)

In 1997, congenital malformations accounted for an estimated 495000 deaths worldwide. ${ }^{1}$ The great majority of these deaths occurred during the first year of life, and thus tend to contribute mostly to infant mortality rate, which is defined as the number of deaths per 1000 live births between birth and exact age one year. ${ }^{2}$ The impact of congenital anomalies on infant mortality depends on many factors, including the prevalence of congenital anomalies, the prevalence of other competing causes of death, the quality and availability of medical and surgical care, and the presence and effectiveness of primary prevention policies. Prenatal diagnosis followed by termination of affected pregnancies may also influence the reported impact of congenital anomalies at or after birth. Because of the many factors involved, infant mortality attributable to congenital anomalies can be expected to vary substantially among countries. In some developing countries, for instance, infant mortality remains very high (as high as 10 per cent in 1995). ${ }^{1}$ In these countries, the leading causes of infant deaths are related to malnutrition and infectious diseases, with congenital anomalies often accounting for 5 per cent or less of the deaths, ${ }^{1}$ although striking geographical variations have been observed. For example, in the 1980s in Latin America and the Caribbean, the proportion of infant deaths attributable to congenital anomalies varied from approximately 2 to 27 per cent and ranked among the five leading causes of infant deaths in that region. ${ }^{3}$ In contrast, in developed countries, the proportion of infant deaths because of congenital malformations tends to be high and has been increasing, even as infant mortality attributable to congenital malformations has fallen. ${ }^{4}$ For example, from 1960 to 1994 in the United States, birth defect specific infant mortality declined 53 per cent (from 36 to 17 per 10000 live births), but congenital anomalies are still the leading cause of infant mortality in that country. ${ }^{5}$ Consistent with these data on infant mortality are reports showing a decline in neonatal mortality attributable to congenital anomalies during the past five decades. ${ }^{6}$ In 1994 in the United States, anomalies of the heart and central nervous system accounted for a substantial proportion of infants deaths (31 and 13 per cent, respectively)..$^{5}$ As improvements in overall infant health promise decreases in deaths attributable to malnutrition and infectious diseases, the relative impact of congenital anomalies on infant mortality can be expected to increase in many parts of the world. However, few studies so far provide an international perspective on current trends. We used population-based data obtained from vital statistics reported from 1950 to 1994 to the World Health Organisation (WHO) to describe international variations and time trends of infant mortality attributable to congenital anomalies during this period.

\section{Methods}

We derived the data for this study from files compiled by WHO from vital statistics reported to WHO by individual countries. The electronic files are publicly available on the WHO web site (http:/www.who.int/whosis/ 
Table 1 Correspondence table of codes for selected congenital anomalies in the ICD* revisions used from 1950 to 1994

\begin{tabular}{|c|c|c|c|c|}
\hline \multirow{2}{*}{$\begin{array}{l}\text { ICD-9 (adopted from } 1979 \text { to 1995) } \\
\text { Code Description }\end{array}$} & \multicolumn{2}{|c|}{ ICD-8 (adopted from 1968 to 1978) } & \multicolumn{2}{|c|}{ ICD-6, ICD-7 (adopted from 1950 to 1967) } \\
\hline & Code & Description & Code & Description \\
\hline B44 Congenital anomalies & A126-A130 & Congenital anomalies & A127-A129 & Congenital anomalies \\
\hline $\begin{array}{l}\text { B440 Spina bifida and hydrocephalus } \\
\text { B441 Other deformities of CNS }\end{array}$ & A126 & Spina bifida & A127 & Spina bifida \\
\hline $\begin{array}{l}\text { B442 Defects of the heart and circulatory } \\
\text { system }\end{array}$ & $\mathrm{A} 127+\mathrm{A} 128$ & $\begin{array}{l}\text { Defects of the heart and circulatory } \\
\text { system }\end{array}$ & A128 & $\begin{array}{l}\text { Defects of the heart and circulatory } \\
\text { system }\end{array}$ \\
\hline $\begin{array}{l}\text { B443 Cleft palate and cleft lip } \\
\text { B444 Other deformities of digestive system } \\
\text { B445 Undescended testis } \\
\text { B446 Congenital dislocation of hip } \\
\text { B447 Other congenital anomalies of } \\
\quad \text { musculoskeletal system }\end{array}$ & A129 & Cleft palate and cleft lip & & \\
\hline B449 All other congenital anomalies & A130 & All other congenital anomalies & A129 & All other congenital anomalies \\
\hline
\end{tabular}

$\star \mathrm{ICD}=$ International Classification of Diseases.

mort/download.htm). We selected the countries on the basis of the availability of relatively complete vital statistics for the period 1950 to 1994. We used data from the following areas and countries: Latin America (Argentina, Chile, Uruguay, Venezuela); Central America (Mexico); the Caribbean (Cuba); North America (United States, Canada); Western Europe (Austria, Belgium, Denmark, Finland, France, Former Federal Republic of Germany, Greece, Ireland, Italy, the Netherlands, Norway, Portugal, Spain, Sweden, Switzerland, and the United Kingdom); Eastern Europe (Bulgaria, former Czechoslovakia, Former Demo- cratic Republic of Germany, Hungary, Poland, Romania, the Russian Federation, and the former Yugoslavia); Asia (Japan); the Middle East (Israel); and the South Pacific (Australia, New Zealand). For countries, such as Germany, the Czech and Slovak Republics, and the former Yugoslav Republics that experienced major border changes during recent years, we used the national boundaries as they existed before 1989 to establish consistency with data from previous years.

An infant death was considered to be attributable to a congenital anomaly if the underlying cause of death included a code for a

Table 2 Infant mortality rates attributable to congenital anomalies, by five year period, in 36 countries, 1950-1994 (source: World Health Organisation). Rates per 10000

\begin{tabular}{|c|c|c|c|c|c|c|c|c|c|}
\hline Country & $\begin{array}{l}1950-54 \\
I M R^{\star}(\%) \dagger\end{array}$ & $\begin{array}{l}1955-59 \\
\operatorname{IMR}(\%)\end{array}$ & $\begin{array}{l}1960-64 \\
\operatorname{IMR}(\%)\end{array}$ & $\begin{array}{l}1965-69 \\
\operatorname{IMR}(\%)\end{array}$ & $\begin{array}{l}1970-74 \\
\operatorname{IMR}(\%)\end{array}$ & $\begin{array}{l}1975-79 \\
\operatorname{IMR}(\%)\end{array}$ & $\begin{array}{l}1980-84 \\
\operatorname{IMR}(\%)\end{array}$ & $\begin{array}{l}1985-89 \\
\operatorname{IMR}(\%)\end{array}$ & $\begin{array}{l}1990-94 \\
\operatorname{IMR}(\%)\end{array}$ \\
\hline \multicolumn{10}{|l|}{ North America } \\
\hline Canada & $52.1(14)$ & $48.2(16)$ & $45.0(17)$ & $41.5(19)$ & $36.6(22)$ & $30.9(25)$ & $27.7(30)$ & $23.5(31)$ & $19.6(31)$ \\
\hline United States & $39.0(14)$ & $37.3(14)$ & $35.8(14)$ & $33.2(15)$ & $29.0(16)$ & $25.9(18)$ & $24.4(21)$ & $21.3(21)$ & $18.7(21)$ \\
\hline \multicolumn{10}{|l|}{ Central-South America } \\
\hline Argentina & & & & $30.2(6)$ & $34.1(6)$ & $35.4(9)$ & $34.6(11)$ & $36.0(14)$ & $36.8(15)$ \\
\hline Chile & & $20.3(2)$ & 20.7 (2) & $29.7(3)$ & $35.2(5)$ & $40.2(9)$ & $37.9(15)$ & $37.3(20)$ & $37.3(25)$ \\
\hline Cuba & & & $35.9(9)$ & $39.5(9)$ & $39.0(12)$ & $39.8(17)$ & $36.0(21)$ & $31.1(24)$ & $26.0(24)$ \\
\hline Mexico & & $18.2(2)$ & $17.1(2)$ & $15.7(2)$ & $15.1(3)$ & $20.7(4)$ & $24.9(6)$ & $21.9(9)$ & $24.9(12)$ \\
\hline Uruguay & & $27.3(6)$ & $26.8(6)$ & $31.3(6)$ & $32.8(8)$ & $37.3(8)$ & $40.4(13)$ & $37.5(15)$ & $36.3(18)$ \\
\hline Venezuela & & $15.2(2)$ & $17.9(4)$ & $20.2(4)$ & $25.0(5)$ & $24.9(7)$ & $24.6(8)$ & $26.2(11)$ & \\
\hline \multicolumn{10}{|l|}{ Western Europe } \\
\hline Ireland & $59.2(14)$ & $66.6(19)$ & $71.2(25)$ & $60.1(26)$ & $50.4(28)$ & $48.0(32)$ & $34.4(33)$ & $27.2(32)$ & 29.1 (39) \\
\hline United Kingdom & $45.8(16)$ & $47.5(20)$ & $45.4(21)$ & $39.6(21)$ & $39.4(22)$ & $35.8(25)$ & $29.4(27)$ & $20.6(23)$ & $14.4(21)$ \\
\hline Norway & 32.9 (14) & $33.9(17)$ & $33.8(19)$ & $29.5(20)$ & $27.1(23)$ & $28.6(30)$ & $25.1(31)$ & $23.3(28)$ & $17.4(29)$ \\
\hline Sweden & $35.3(18)$ & $33.9(20)$ & $32.9(21)$ & $30.6(24)$ & $30.4(29)$ & $28.5(36)$ & $24.9(36)$ & $21.6(36)$ & $19.2(35)$ \\
\hline Finland & $38.2(12)$ & $44.6(17)$ & $38.1(20)$ & $30.9(20)$ & $30.3(26)$ & $26.7(31)$ & $26.1(40)$ & $22.4(37)$ & $18.2(36)$ \\
\hline Denmark & $45.2(16)$ & $43.1(18)$ & $42.8(21)$ & $35.9(22)$ & $33.8(27)$ & $28.7(31)$ & $25.5(32)$ & $25.2(32)$ & $21.9(34)$ \\
\hline West Germany & $49.3(11)$ & $49.6(13)$ & $46.5(16)$ & $40.3(17)$ & $41.4(18)$ & $36.0(22)$ & $28.9(26)$ & $21.4(26)$ & $19.0(27)$ \\
\hline Netherlands & $49.5(21)$ & $46.3(26)$ & $41.8(27)$ & $36.2(26)$ & $31.9(27)$ & $29.1(30)$ & $27.2(32)$ & $24.8(34)$ & $23.0(36)$ \\
\hline Belgium & $41.6(10)$ & $50.0(14)$ & $47.2(17)$ & $47.4(21)$ & $42.3(22)$ & $35.1(25)$ & $29.6(27)$ & $24.4(26)$ & $21.4(26)$ \\
\hline France & $32.7(8)$ & $36.7(13)$ & $36.5(17)$ & $33.9(20)$ & $28.3(21)$ & $24.0(21)$ & $20.7(22)$ & $16.4(21)$ & $13.7(20)$ \\
\hline Austria & & $44.5(10)$ & $44.6(14)$ & $43.9(16)$ & $39.2(16)$ & $38.5(23)$ & $34.2(27)$ & $26.0(27)$ & $21.6(31)$ \\
\hline Switzerland & $45.2(16)$ & $42.4(18)$ & $41.8(20)$ & $36.5(22)$ & $34.8(26)$ & $31.6(33)$ & $28.5(36)$ & $24.0(34)$ & $21.4(35)$ \\
\hline Italy & $40.1(7)$ & $37.4(8)$ & $36.0(9)$ & $34.7(10)$ & $34.8(13)$ & $32.5(18)$ & $29.9(23)$ & $23.7(25)$ & $20.5(25)$ \\
\hline Greece & & & $32.8(8)$ & $39.9(12)$ & $43.0(16)$ & $45.6(22)$ & $46.5(30)$ & $36.7(31)$ & $41.4(47)$ \\
\hline Portugal & & $22.4(3)$ & $24.4(3)$ & $26.9(4)$ & $32.8(7)$ & $38.7(12)$ & $36.5(18)$ & $31.7(22)$ & $26.5(28)$ \\
\hline Spain & $17.6(3)$ & $16.0(4)$ & $18.2(5)$ & $20.2(8)$ & $24.6(16)$ & $37.3(23)$ & $30.7(27)$ & $24.4(28)$ & $22.7(32)$ \\
\hline \multirow{2}{*}{\multicolumn{10}{|c|}{ Eastern Europe }} \\
\hline & & & & & & & & & \\
\hline Former Yugoslavia & & & $16.1(2)$ & $20.5(3)$ & $24.4(5)$ & $24.7(7)$ & $28.3(9)$ & $27.6(11)$ & $27.6(14)$ \\
\hline Bulgaria & & & $25.1(8)$ & $24.9(8)$ & $29.6(11)$ & $30.9(14)$ & $35.4(20)$ & $36.5(25)$ & $43.1(27)$ \\
\hline Former Czechoslovakia & $41.5(10)$ & $42.6(14)$ & $43.3(19)$ & $44.2(19)$ & $39.8(19)$ & $39.7(20)$ & $41.4(25)$ & $33.9(27)$ & $29.1(26)$ \\
\hline East Germany & & & & & $30.4(19)$ & $30.6(22)$ & $24.1(21)$ & $21.3(25)$ & $19.6(27)$ \\
\hline Hungary & & $63.7(11)$ & $63.9(14)$ & $62.9(17)$ & $55.4(16)$ & $53.1(20)$ & $45.4(22)$ & $38.8(22)$ & $31.3(24)$ \\
\hline Poland & & $45.8(6)$ & $46.2(9)$ & $45.5(12)$ & $48.7(18)$ & $49.3(21)$ & $48.7(24)$ & $46.1(27)$ & $41.0(28)$ \\
\hline Romania & & $35.5(5)$ & $33.2(5)$ & $33.6(7)$ & $33.5(8)$ & $37.3(12)$ & $42.9(16)$ & $50.4(19)$ & $38.9(16)$ \\
\hline Russian Federation & & & & & & & $33.1(16)$ & $37.9(20)$ & $39.5(21)$ \\
\hline \multicolumn{10}{|l|}{ South Pacific and Fapan } \\
\hline Japan & $21.8(4)$ & $19.7(5)$ & $19.8(8)$ & $20.8(13)$ & $21.4(18)$ & $21.3(24)$ & $18.6(28)$ & $16.7(33)$ & $15.9(36)$ \\
\hline New Zealand & $39.9(15)$ & $38.6(16)$ & $37.8(18)$ & $36.4(20)$ & $34.5(21)$ & $33.9(24)$ & $29.0(24)$ & $26.0(24)$ & $21.4(27)$ \\
\hline Australia & $37.9(16)$ & $39.0(18)$ & $37.9(19)$ & $33.1(18)$ & $34.6(20)$ & $33.0(26)$ & $29.1(29)$ & $23.6(27)$ & $18.3(27)$ \\
\hline \multicolumn{10}{|l|}{ Total } \\
\hline attributable to congenital anomalies & $36.1(9)$ & $35.1(9)$ & $33.0(9)$ & $30.8(9)$ & $29.4(10)$ & $29.6(11)$ & $28.4(17)$ & $26.4(18)$ & $24.0(20)$ \\
\hline attributable to any cause & 398.5 & 401.3 & 379.4 & 331.0 & 285.6 & 265.1 & 166.5 & 148.1 & 121.1 \\
\hline
\end{tabular}

${ }^{\star} \mathrm{IMR}=$ infant mortality rate, deaths of infants under 1 year of age per 10000 live births. $\uparrow \%=$ per cent of total infant mortality (all causes). 


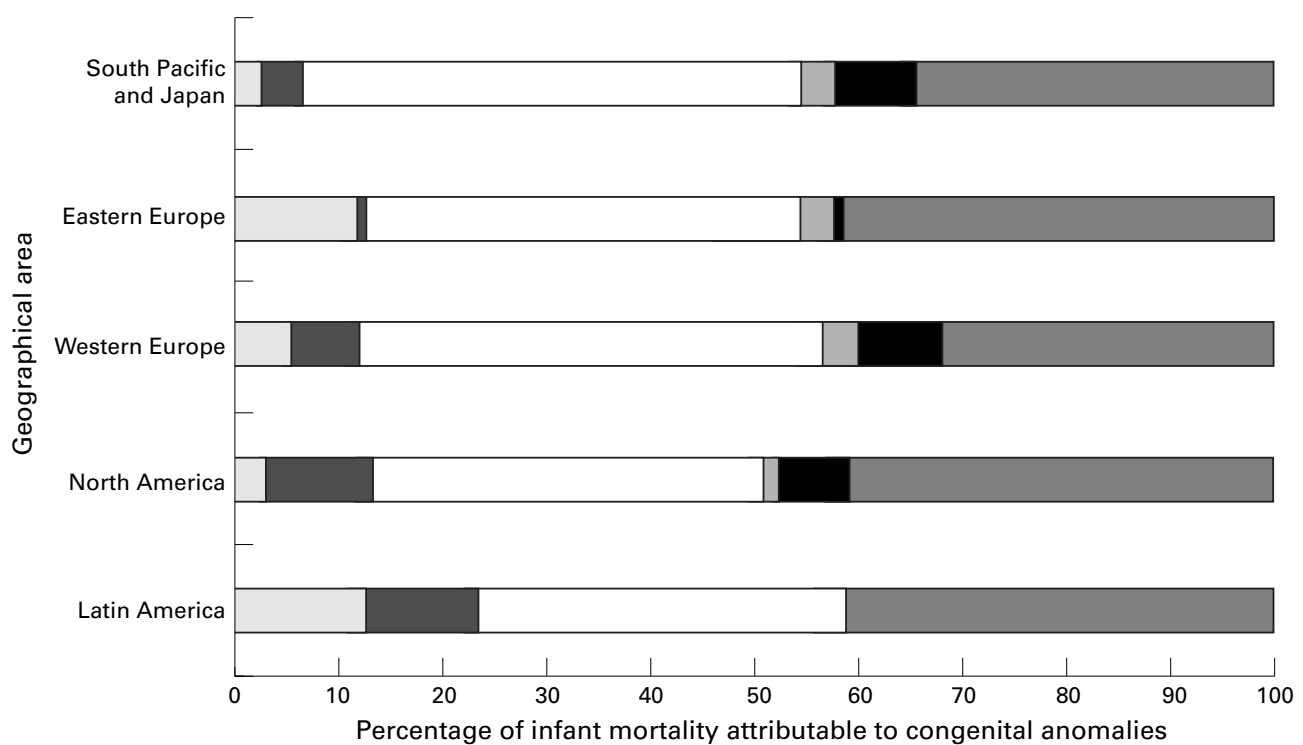

Spina bifida

Other central nervous system

Figure 1 Contribution of specific defects to infant mortality attributable to congenital anomalies, by geographical area, 1990-1994 (sources: World Health Organisation).

congenital anomaly. Codes for congenital anomalies were defined as those listed in the congenital anomalies section of the International Classification of Disease (ICD), revision six to nine (ICD-6, ICD-7, ICD-8, and ICD-9). Table 1 shows the correspondence among some WHO codes adopted with the ICD revisions. In the ICD-9 system, implemented in 1979, the WHO code B440 includes both spina bifida and hydrocephalus (ICD codes 741 and 742.3), whereas in ICD-6 through ICD-8 it included spina bifida alone. We computed infant mortality rates using as the denominator the yearly number of live births. The legal requirements for the reporting of fetal deaths and live births vary from country to country and even within countries. WHO recommends that, if possible, all fetuses and infants weighing at least $500 \mathrm{~g}$ at birth, whether alive or dead, should be included in the statistics. When information on birth weight is unavailable, the corresponding criteria for gestational age (22 completed weeks) or body length $(25 \mathrm{~cm}$ crown to heel) should be used. The criteria for deciding whether an event has taken place within the perinatal period should be applied in the order: (1) birth weight, (2) gestational age, (3) crown to heel length. ${ }^{7}$

We used the Spearman coefficient ${ }^{8}$ to test the correlation between infant mortality attributable to congenital anomalies and a country's per capita gross domestic product. ${ }^{9}$

\section{Results}

TRENDS IN INFANT MORTALITY ATTRIBUTABLE TO CONGENITAL ANOMALIES, 1950-1994

In the countries that we studied, total infant mortality decreased about 70 per cent from

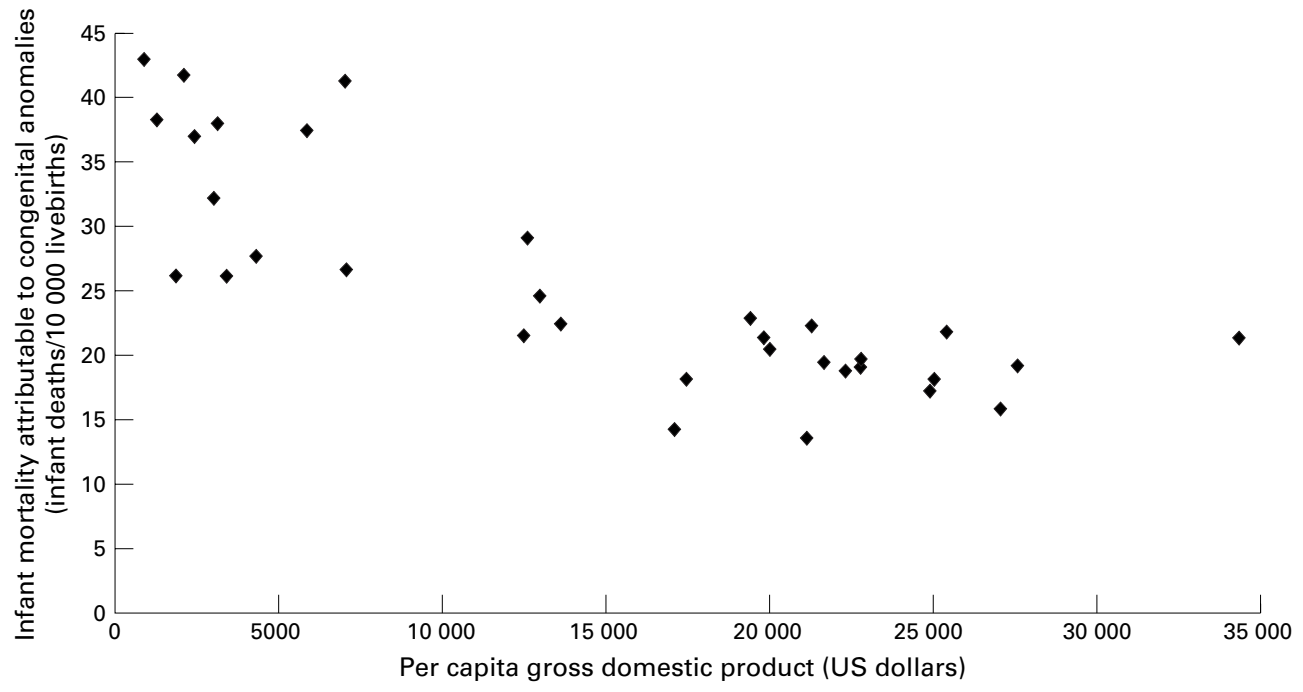

Figure 2 Infant mortality attributable to congenital anomalies in relation to per capita gross domestic product in 35 countries, 1990-1994 (source: World Health Organisation). 
1950 to 1994 (table 2). Infant mortality attributable to congenital anomalies decreased approximately 35 per cent (table 2 ). Such percentages represent an average among all countries studies. Of these countries, 19 contributed data for the whole study period, and were mostly in Western Europe, North America and Oceania. Considering only these 19 countries, the decrease was 81 per cent and 50 per cent for total infant mortality and infant mortality attributable to congenital anomalies, respectively. However, in some areas (Spain, Portugal, Mexico, and Eastern Europe) infant mortality attributable to congenital anomalies did remain stable or increased. The increase was most apparent in Romania (approximately from 35 per 10000 in the period 1955-1964 to 45 per 10000 in the period 1985-1994) and Bulgaria (from 25 per 10000 in 1960-64 to 40 per 10000 in 1985-94) (table 2). The decrease in infant mortality attributable to congenital anomalies was proportionally larger in those countries (Canada, Germany, United Kingdom, the Netherlands, and Denmark) where it had been highest at the beginning of the study period. In the period 1990 through 1994, infant mortality attributable to congenital anomalies was, on average, 24 per 10000 (table 2).

PROPORTIONAL IMPACT OF CONGENITAL ANOMALIES ON INFANT MORTALITY

Infant mortality attributable to congenital anomalies, as a proportion of total infant mortality, varied worldwide throughout the study period (table 2), with marked differences among geopolitical areas. For instance, in Latin America the proportion of infant deaths attributable to congenital anomalies increased from 2-6 per cent in the 1950 s to $12-25$ per cent in the early 1990s. In Norway and Sweden the proportion increased to 35 per cent or more. In the United Kingdom, the proportion peaked at 29 per cent in the period 1980-84 and then declined to 21 per cent in 1994 .

Because of the adoption of ICD-9 coding in 1979 , we were able to assess the impact of specific congenital anomalies on infant mortality
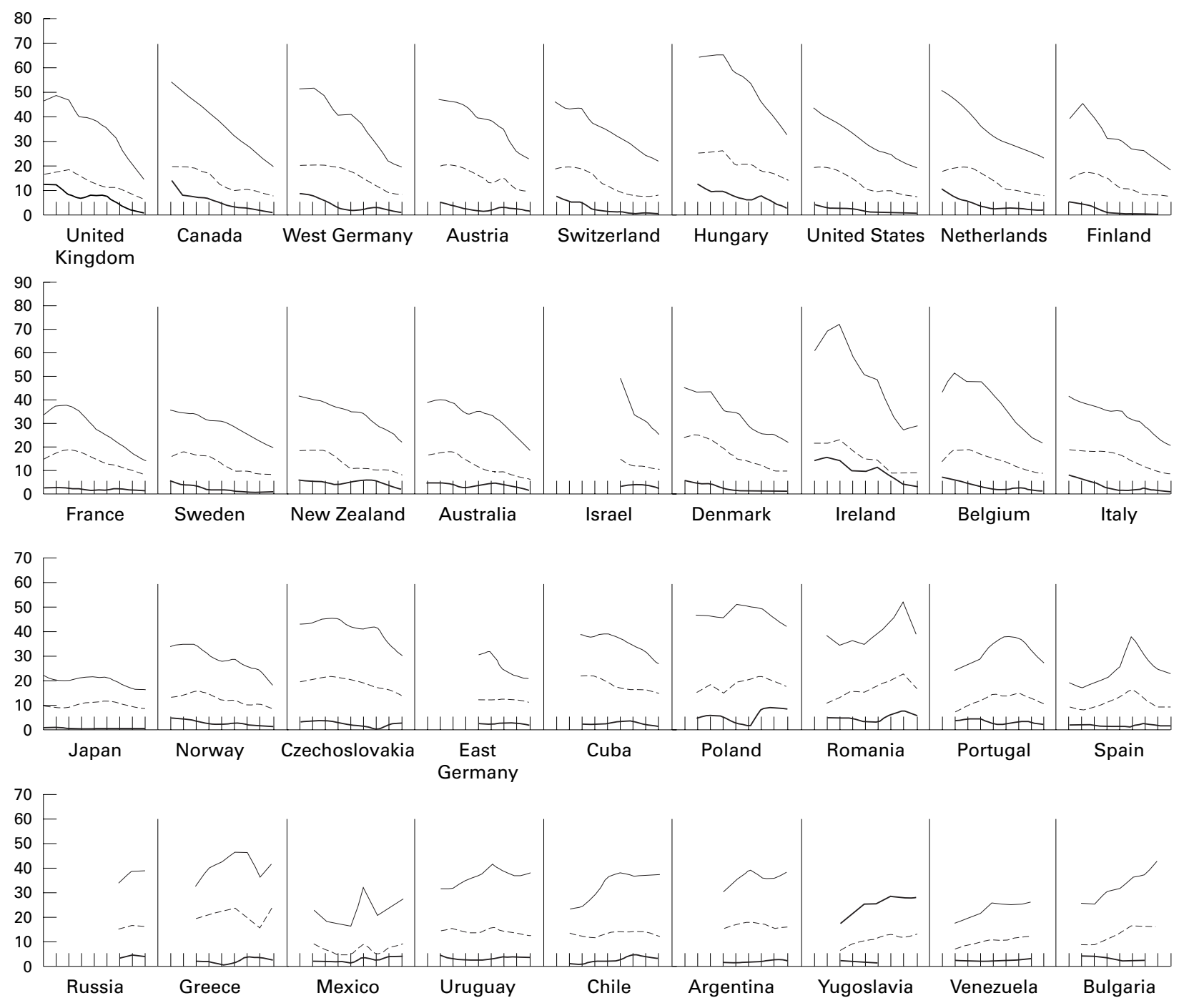

$$
\text { - Spina bifida --- Heart defects - Total }
$$

Figure 3 Infant mortality attributable to congenital anomalies, total, attributable to spina bifida, and attributable to heart defects, ordered by percentage decrease in the period between 1950 and 1994. Rates are per 10000 live births, time in per five year periods (source: World Health Organisation). 
Table 3 International comparison of infant mortality attributable to congenital anomalies, overall and for selected anomalies, 1990-1994 (source: World Health Organisation)

\begin{tabular}{|c|c|c|c|c|c|c|c|c|c|c|c|c|}
\hline \multirow[b]{2}{*}{ Country } & \multirow[b]{2}{*}{ Years } & \multicolumn{3}{|c|}{ Spina bifida } & \multicolumn{3}{|c|}{ Cardiac defects } & \multicolumn{3}{|c|}{ Other defects } & \multicolumn{2}{|l|}{ Total } \\
\hline & & $\begin{array}{l}\text { Number } \\
\text { of deaths }\end{array}$ & $\begin{array}{l}\text { Mortality } \\
\text { per } 10 \\
000\end{array}$ & $\begin{array}{l}\text { Percentage } \\
\text { of total }\end{array}$ & $\begin{array}{l}\text { Number } \\
\text { of deaths }\end{array}$ & $\begin{array}{l}\text { Mortality } \\
\text { per } 10 \\
000\end{array}$ & $\begin{array}{l}\text { Percentage } \\
\text { of total }\end{array}$ & $\begin{array}{l}\text { Number } \\
\text { of deaths }\end{array}$ & $\begin{array}{l}\text { Mortality } \\
\text { per } 10 \\
000\end{array}$ & $\begin{array}{l}\text { Percentage } \\
\text { of total }\end{array}$ & $\begin{array}{l}\text { Number } \\
\text { of deaths }\end{array}$ & $\begin{array}{l}\text { Mortality } \\
\text { per } 10 \\
000\end{array}$ \\
\hline \multicolumn{13}{|l|}{ North America } \\
\hline Canada & $90-94$ & 211 & 1.1 & 5 & 1494 & 7.5 & 38 & 2179 & 11.0 & 56 & 3884 & 19.61 \\
\hline United States & $90-93$ & 934 & 0.6 & 3 & 11398 & 7.0 & 37 & 18170 & 11.1 & 60 & 30502 & 18.67 \\
\hline \multicolumn{13}{|l|}{ Central-South America } \\
\hline Mexico & $90-93$ & 3989 & 3.6 & 14 & 9317 & 8.4 & 34 & 14263 & 12.9 & 52 & 27569 & 24.87 \\
\hline Cuba & 90 & 24 & 1.3 & 5 & 270 & 14.5 & 56 & 191 & 10.2 & 39 & 485 & 25.98 \\
\hline Chile & 90,92 & 208 & 3.5 & 9 & 750 & 12.5 & 33 & 1285 & 21.4 & 57 & 2243 & 37.30 \\
\hline Uruguay & 90 & 19 & 3.4 & 9 & 68 & 12.0 & 33 & 118 & 20.9 & 58 & 205 & 36.27 \\
\hline Argentina & $90-91$ & 336 & 2.4 & 7 & 2185 & 15.7 & 43 & 2615 & 18.7 & 51 & 5136 & 36.83 \\
\hline \multicolumn{13}{|l|}{ Western Europe } \\
\hline Ireland & $90-92$ & 47 & 3.0 & 10 & 143 & 9.1 & 31 & 268 & 17.0 & 59 & 458 & 29.12 \\
\hline United Kingdom & $90-94$ & 244 & 0.6 & 4 & 2473 & 6.4 & 44 & 2877 & 7.4 & 51 & 5594 & 14.40 \\
\hline Norway & $90-93$ & 22 & 0.9 & 5 & 188 & 7.8 & 45 & 210 & 8.7 & 50 & 420 & 17.39 \\
\hline Sweden & $90-93$ & 24 & 0.5 & 3 & 383 & 7.8 & 41 & 532 & 10.9 & 57 & 939 & 19.23 \\
\hline Finland & $90-94$ & & & & 252 & 7.7 & 42 & 346 & 10.5 & 58 & 598 & 18.23 \\
\hline Denmark & $90-93$ & 27 & 1.0 & 5 & 248 & 9.4 & 43 & 300 & 11.4 & 52 & 575 & 21.86 \\
\hline West Germany & 90 & 84 & 1.2 & 6 & 590 & 8.1 & 43 & 709 & 9.7 & 51 & 1383 & 19.02 \\
\hline Netherlands & $90-94$ & 218 & 2.2 & 10 & 762 & 7.7 & 34 & 1281 & 13.0 & 57 & 2261 & 22.96 \\
\hline Belgium & $90-91$ & 35 & 1.4 & 7 & 216 & 8.7 & 40 & 283 & 11.3 & 53 & 534 & 21.39 \\
\hline France & $90-94$ & 275 & 0.7 & 5 & 2745 & 7.4 & 54 & 2020 & 5.5 & 40 & 5040 & 13.67 \\
\hline Austria & $90-95$ & 85 & 1.5 & 7 & 513 & 9.2 & 43 & 605 & 10.9 & 50 & 1203 & 21.61 \\
\hline Switzerland & $90-94$ & 19 & 0.4 & 2 & 337 & 8.0 & 37 & 551 & 13.0 & 61 & 907 & 21.40 \\
\hline Italy & $90-92$ & 178 & 1.0 & 5 & 1494 & 8.8 & 43 & 1815 & 10.6 & 52 & 3487 & 20.45 \\
\hline Greece & $90-94$ & 115 & 2.2 & 5 & 1200 & 23.3 & 56 & 816 & 15.9 & 38 & 2131 & 41.42 \\
\hline Portugal & $90-94$ & 96 & 1.7 & 6 & 583 & 10.2 & 38 & 837 & 14.7 & 55 & 1516 & 26.54 \\
\hline Spain & $90-93$ & 185 & 1.2 & 5 & 1468 & 9.3 & 41 & 1936 & 12.3 & 54 & 3589 & 22.72 \\
\hline Israel & $90-94$ & 115 & 2.1 & 9 & 539 & 9.9 & 40 & 687 & 12.6 & 51 & 1341 & 24.56 \\
\hline \multicolumn{13}{|l|}{ Eastern Europe } \\
\hline Bulgaria & & & & & 740 & 16.3 & 38 & 1216 & 26.8 & 62 & 1956 & 43.08 \\
\hline Czechoslovakia, Former & $90-91$ & 103 & 2.5 & 8 & 545 & 13.0 & 45 & 568 & 13.6 & 47 & 1216 & 29.05 \\
\hline East Germany & 90 & 23 & 1.3 & 7 & 187 & 10.5 & 54 & 139 & 7.8 & 40 & 349 & 19.55 \\
\hline Hungary & $90-95$ & 187 & 2.6 & 8 & 1010 & 14.0 & 45 & 1053 & 14.6 & 47 & 2250 & 31.28 \\
\hline Poland & $90-95$ & 2478 & 8.1 & 20 & 5228 & 17.1 & 42 & 4834 & 15.8 & 39 & 12540 & 40.97 \\
\hline Rumania & $90-93$ & 635 & 5.8 & 15 & 1837 & 16.7 & 43 & 1806 & 16.4 & 42 & 4278 & 38.88 \\
\hline Russian Federation & $90-94$ & 3111 & 3.8 & 10 & 13239 & 16.2 & 41 & 15857 & 19.4 & 49 & 32207 & 39.48 \\
\hline \multicolumn{13}{|l|}{ Oceania and Fapan } \\
\hline New Zealand & $90-93$ & 38 & 1.6 & 7 & 181 & 7.6 & 35 & 291 & 12.2 & 57 & 510 & 21.40 \\
\hline Australia & $90-94$ & 155 & 1.2 & 7 & 740 & 5.7 & 31 & 1455 & 11.3 & 62 & 2350 & 18.26 \\
\hline
\end{tabular}

for the later part of the study period. Figure 1 summarises the findings for 1990-1994 by major geographical area. Central nervous system defects accounted for a relatively higher proportion of infant deaths in Latin America compared with other areas, whereas the proportion attributable to heart defects was highest in the South Pacific and Japan, and that attributable to anomalies of the digestive systems was highest in Western and Eastern Europe.

RELATION WITH PER CAPITA GROSS DOMESTIC PRODUCT

Infant mortality attributable to congenital anomalies in the countries examined showed a strong inverse correlation with per capita gross domestic product $(r=-0.8, \mathrm{p}<0.001)$ for the period 1990-1994 (fig 2). Infant mortality attributable to congenital anomalies as a proportion of all infant deaths correlated directly with per capita gross domestic product $(r=0.5, \mathrm{p}<0.005)$.

INFANT MORTALITY ATTRIBUTABLE TO SPECIFIC CONGENITAL ANOMALIES

Data were available for cardiac defects since 1950, for spina bifida from 1950 to 1977 , and for spina bifida plus hydrocephalus beginning in 1978. In the United States, Canada, Cuba, Australia, New Zealand, Israel, Japan, and Western Europe, infant mortality attributable to spina bifida declined throughout the study period (fig 3), and in the period 1990-94 was below 2.5 per 10000 live births in almost every country studied (table 3). A similar pattern was found in Eastern Europe, with the exception of Poland and Romania. In these two countries, infant mortality attributable to spina bifida increased or fluctuated and was approximately three times higher than in the rest of Europe. In most Central and Latin American countries, rates were stable or ranged slightly upward, with the exception of Cuba, where spina bifida related infant mortality decreased.

Infant mortality attributable to heart defects also decreased in Western countries and in Cuba, Israel, Australia, and New Zealand. In these countries, with the exception of Cuba, infant mortality attributable to heart defects in the period 1990-1994 was less than 10 per 10000 live births, approximately half the average rate reported in the period 1950-54. In Latin America the rate was on average 15 per 10000 and was stable. In most of Eastern Europe infant mortality attributable to cardiac defects was also stable, with the exception of Bulgaria and Romania, where rates were twice those reported in the rest of Europe. In Japan, rates were 9.5 per 10000 in the period 1950 1954 , increased to a peak of 12 per 10000 in 1975-1979 and then declined to 8 per 10000 in 1990-94. 


\section{Discussion}

We found that congenital malformations are currently an important cause of infant death in many developed and developing countries, both in absolute terms and as a proportion of all infant deaths. In 1990-1994, between 35 and 40 per cent of all deaths of infants younger than one year of age were attributable to congenital anomalies in North Europe (that is, Scandinavian countries, Ireland, and the Netherlands). This proportion was about 30 per cent in the other developed countries and about 20 per cent in some South American nations. This proportion also correlates with a country's average economic wealth, as measured by the per capita gross domestic product. In absolute terms, however, infant mortality attributable to congenital anomalies caused more infant deaths in poorer countries than in wealthier countries. The study of trends from 1950 onward revealed that, whereas total infant mortality decreased in all countries, trends for infant mortality attributable to congenital malformations were more mixed. Thus, although in most countries the rate decreased, albeit more slowly than that of total infant mortality, infant mortality attributable to congenital anomalies was stable or increased in some countries in Latin America and Eastern and Southern Europe. For example, infant mortality attributable to congenital anomalies increased in Portugal and Spain between 1970 and 1975, and in Romania and Bulgaria between 1985 and 1990. It is unclear what factors underlie these stable or upward trends. It has been suggested that in Portugal such a trend may be attributable in part to improved diagnosis and case notification associated with an increase in hospital-based deliveries (A Leitão 1999, personal communication).

The limitations of the study reflect the limitations of our data source, which was the database of vital statistics maintained by WHO that was based on reports from individual countries. Because we were able to study in some detail only 36 countries (mostly those in Europe, the Americas, Japan, and the South Pacific), we were unable to assess infant mortality attributable to congenital anomalies in many parts of the world that have a high birth rate and presumably significant infant health challenges. These areas include all of Africa, the Indian subcontinent, and most of Asia. Even for those countries that we were able to study, our analyses were restricted to the type of congenital anomalies that are included by WHO in its list of reportable malformations. A further limitation of our study was the potential for error and variability inherent in using vital statistics to classify causes of death. The terminology on death certificates or the application of coding rules for the International Classification of Disease may differ across countries or even within the same country across the years, thus limiting comparability among countries and the study of time trends. Even the definition of infant mortality may be open to interpretation, in that very early deaths, particularly among very premature babies or babies with congenital anomalies could be
KEY POINTS

- Infant mortality decreased on average 68.8 per cent from 1950 to 1994 . Infant mortality attributable to congenital anomalies decreased 33.4 per cent and accounted for an increasing fraction of the total infant mortality.

- Infant mortality attributable to congenital anomalies was higher in poor countries than in wealthier countries. However, as a proportion of all infant deaths, infant mortality attributable to congenital anomalies was higher in wealthier than in poorer countries.

- Many deaths are still caused by spina bifida, whose occurrence can be reduced by the consumption of sufficient amounts of folic acid.

- In some countries in Central and Latin America and in Eastern Europe, infant mortality attributable to congenital anomalies seems to have increased in recent years.

misclassified as stillbirths or late abortions. ${ }^{10}$ WHO data take into account only the primary cause of death, and deaths of infants with congenital malformations may be attributed to other factors even if the congenital malformation was indeed the underlying cause of death. For instance, a new neonatal death certificate was introduced in England and Wales in 1986 that allowed multiple causes of death to be reported. However, only the first recorded condition was reported to WHO. It is intriguing therefore that a large decline in anencephaly as a cause of death was observed at around that time. Finally, we were unable to evaluate the impact of prenatal diagnosis of congenital malformations and termination of affected pregnancies. Selective termination of pregnancies affected by congenital malformations would reduce the number of an affected infant that are born and, if common enough, would result in a decline in infant mortality attributable to congenital anomalies. The interpretation of such a decline must take into account the notion that no case of disease has been actually prevented. Because of the relatively recent introduction of effective methods of prenatal diagnosis, their impact would be most felt in the most recent period covered by our study.

The strengths of the study reflect the strengths of vital records as a source of mortality data. Vital records are one of the few established, longstanding systems in which systematically recorded data cover essentially the whole population, making these records useful resources for tracking population-wide mortality over long periods.

Our findings are consistent with the studies on perinatal mortality from hospital-based registries in Europe, the United States, and Canada. These studies showed a 65 to 80 per cent decline in total perinatal mortality during the past 50 years, whereas the proportion of perinatal deaths attributable to congenital 
anomalies increased by up to 30 per cent. ${ }^{6}$ The reduction of perinatal mortality was in great part associated with progress in the medical and surgical management of some of the major causes of perinatal deaths, including haemolytic disease of the newborn, labour complications and birth injury, asphyxia, infections, and premature birth. ${ }^{11}{ }^{12}$ The decline in total infant mortality reported in our study probably reflects this progress. The slower decline in infant mortality attributable to congenital anomalies suggests that progress in the care of infants with congenital malformations has been less successful or less pervasive in the population. Because many structural anomalies require prompt and often complex medical and surgical care, it is not unexpected that progress seems to have been slower in countries that can devote less of their collective wealth to the care of infants with congenital malformations. Factors other than changes in survival also may have played a part in the observed trends of infant mortality attributable to congenital anomalies. As mentioned previously, selective termination of an affected pregnancy is likely to have had an impact, particularly in the last two decades of the study and in countries where prenatal diagnosis is more prevalent and pregnancy termination is legal. This issue raises the question whether the lowest mortality attributable to congenital anomalies is unconditionally optimal. In the case of spina bifida, for example, the contrast is between, on the one hand, preventing disease by periconceptional folic acid use or improving survival among the affected by optimal medical and surgical treatment, and, on the other hand, terminating affected pregnancies. It is critical that public health professionals and policy makers recognise, assess, and monitor individually these three modes of action. Changes in ascertainment, diagnostic techniques, and reporting practices have the potential of increasing the apparent rate of congenital malformations. Nevertheless, the finding that in some countries in South America and in Eastern Europe infant mortality attributable to congenital anomalies is not decreasing or is actually increasing is of concern and should be investigated to assess the situation and to identify causes and prevention opportunities. Finally, the slower decline of infant mortality attributable to congenital anomalies compared with that attributable to other causes underscores the urgent need to find effective means of primary prevention and to implement those that are known. Spina bifida, for example, caused more than 16000 deaths in the countries studied in 1990-1994. That perhaps half or more of these deaths could have been prevented by maternal consumption of sufficient levels of folic $\operatorname{acid}^{13}$ is a reminder of the continuing challenges facing medical professionals and public health officials in decreasing the burden of mortality attributable to congenital malformations worldwide.

The authors acknowledge WHO as the source of the data. The authors, and not WHO, are solely responsible for the analyses, interpretations and conclusions of such data. The authors thank Dr Maria de Jesus Feijóo for her useful comments.

Conflicts of interest: none.

1 World Health Organization. World Health Report 1998. Geneva: WHO, 1998:43-47.

2 World Health Organization. World Health Report 1999. Geneva: WHO.

3 Pan American Health Organization. Health conditions in the Americas 1986. Washington DC: PAHO, 1986.

4 World Health Organization. World Health Statistics Annual 1993. Geneva: WHO, 1997.

5 Petrini J, Damus K, Johnston RB Jr. An overview of infant mortality and birth defects in the United States. Teratology mortality and birt

6 Kalter H. Five-decade international trends in the relation of perinatal mortality and congenital malformations: stillbirth and neonatal death compared. Int F Epidemiol 1991;20: $173-9$

7 International Classification of Disease 10th revision. Geneva: WHO, 1992:vol 2, 131

8 Spearman C. The proof and measurement of association between two things. Am $\mathcal{F}$ Psychol 1904;15:72-101.

9 Microsoft Encarta 99. World Atlas. Microsoft Corporation, 1998.

10 Sachs BP, Fretts RC, Gardner R, et al. The impact of extreme prematurity and congenital anomalies on the interpretation of international comparisons of infant mortality. Obstet Gynecol 1995;85:941-6.

11 Edouard L, Alberman E. National trends in the certified causes of perinatal mortality, 1968 to 1978 . Br f Obstet causes of perinatal mort
Gynaecol 1980;87:833-8.

12 Manniello RL, Farrell PM. Analysis of United States neonatal mortality statistics from 1968 to 1974 , with neonatal mortality statistics from 1968 to 1974 , with specific reference to changing trends in
Am $\mathcal{F}$ Obstet Gynecol 1977;129:667-74.

13 Holmes L, Harris J, Oakley GP Jr, et al. Teratology Society Consensus Statement on use of folic acid to reduce the risk of birth defects. Teratology 1997;55:381. 